\title{
APRESENTAÇÃO DO V. 22, N.1, 2020, DE AlEA. ESTUdOS NeOLATINOS
}

Presentation of V. 22, ISSUE 1, OF Alea. Estudos Neolatinos

\section{Elena Palmero González \\ ORCID 0000-0003-2396-2539} Universidade Federal do Rio de Janeiro
Rio de Janeiro, RJ, Brasil

A área dos Estudos Coloniais é por definição heterogênea e multidisciplinar. Os trabalhos produzidos nesse campo transitam por saberes táo diversos e complementares como a história, a literatura, a geografia, as artes, a política, a etnografia, a linguística, a sociologia, entre outros. Tratase, conforme argumentam os organizadores deste volume da Alea, de um domínio tentativo, feito de interseçōes e de discursos em escrutínio, mas que ao mesmo tempo se apresenta com um alto grau de especificidade, se nos atentamos para seus principais temas e debates.

O presente volume da Alea pretende interpelar esse vasto campo, acompanhando suas discussōes, sua evoluçáo como campo disciplinar e, sobretudo, pensando o lugar que os Estudos Coloniais ocupam no pensamento contemporâneo. Reunimos, assim, o trabalho de um grupo de pesquisadores de diferentes universidades latino-americanas, que discorrem por temas variados do universo colonial ibero-americano, articulando em suas propostas a problematização teórica, o trabalho historiográfico e a reflexão crítica. O leitor encontrará nas páginas deste volume instigantes reflexóes em torno à própria noção de colonialidade e suas correlatas (decolonialidade, pós-colonialidade), e em torno a outros conceitos que circulam no âmbito contemporâneo dos Estudos Coloniais e Pós-coloniais, tais como hegemonia ou marginalidade. Também poderá acessar ao estudo pontual de figuras (La Quintrala, Manco Cápac), de topos (cidades, edifícios, corpos), de suportes (a letra, as linguagens 
não tipográficas, a oralidade) e de temas do universo colonial, deparando-se com sugestivos exercícios interpretativos em relação a tradiçóes, manifestaçôes arquitetônicas e urbanísticas, línguas e textos literários diversos.

A partir de diferentes perspectivas metodológicas, os textos aqui reunidos discutem como a aparição da América no horizonte europeu do século XV consolidou a expansão dos impérios e domínios ultramarinos da época, redefiniu radicalmente a ordem geopolítica vigente e as formas de vida das populaçóes locais, impus novas formas de opressão e de convivência e afirmou as bases simbólicas e econômicas de um sistema-mundo moderno, que perdura até hoje.

Além dos quinze artigos que compóem o dossiê temático proposto na chamada e da valiosa introdução dos organizadores do volume, que traça pautas de leitura necessárias para o leitor menos familiarizado com o tema, deixamos espaço para duas seçóes já tradicionais em nossa revista, Tradução e Resenhas.

A obra do grande poeta espanhol José Angel Valente ganha espaço na primeira, através de um excelente trabalho de tradução dos dezessete poemas de tema erótico que integram a primeira parte de Mandorla (1982). Trata-se da primeira traduçáo de textos desse curioso livro de Valente, um escritor que somente foi traduzido em Brasil em 2018 (Não amanhece o cantor) e que merecia maior atenção das editoras brasileiras. Aproveitamos para deixar nosso agradecimento à Agência Carmen Balcells, que autorizou a publicação parcial da obra e sua tradução nas páginas da Alea.

$\mathrm{Na}$ seção de Resenhas, incluímos uma dedicada ao livro de Margarita Zamora Sobre Lenguaje, autoridad e historia indigena en los Comentarios reales de los Incas. Trata-se de uma obra clássica nos estudos da obra do Inca Garcilaso, publicada originalmente em inglês, que ganha uma edição corrigida em espanhol em 2018 graças à tradução de Juan Rodríguez Piñero e Vanina M. Teglia. O outro texto resenhado é El continente vacío. La conquista del Nuevo Mundo y la conciencia moderna, do professor e filósofo espanhol Eduardo Subirat. A singularidade desse trabalho é que se trata de uma auto-resenha da edição de 2019 do livro, o que lhe concede um particular valor autobiográfico e testemunhal à apresentação da obra.

No intuito de confrontar a pesquisa que se produz na academia brasileira com a produzida em outros eixos do mundo, e como é de praxe em nossa revista, participaram no volume pesquisadores de diferentes universidades. Do Chile, contamos com a colaboração de professores pesquisadores da Universidad Andrés Bello, da Universidad de Chile, da Universidad de San Sebastián, da Universidad Católica del Maule e da Universidad de los Andes; da Argentina recebemos as colaboraçóes de pesquisadores da Universidade de Buenos Aires, da Universidad Nacional de La Plata e da Universidad Católica Argentina; do 
México, participam pesquisadores da Universidad del Claustro de Sor Juana e da Universidad Autónoma de la Ciudad de México. No caso do Brasil, contamos com a colaboração de pesquisadores da Universidade Federal de Rondônia, da Universidade Federal Rural de Pernambuco, da Universidade do Estado do Rio de Janeiro, da Pontifícia Universidade Católica do Rio de Janeiro, e da PUC-RS. Nas seçôes de Tradução e Resenhas colaboraram professores da Universidade Federal do Amazonas, da Universidad de Buenos Aires e da New York University. Agradecemos a participação de todos e, de maneira especial, dos Editores Convidados, professores da Universidad de Buenos Aires e da Universidade de Pernambuco, que fizeram possível esse concerto de vozes. Esperamos que esse trabalho seja do agrado dos nossos leitores.

\section{Referências}

SUBIRATS, Eduardo. El continente vacio. La conquista del Nuevo Mundo y la conciencia moderna. Guadalajara: Universidad de Guadalajara, 2019.

VALENTE, José Angel. Mandorla. Madrid: Ed. Cátedra, 1982.

VALENTE, José Angel. Não amanhece o cantor. Trad. Saturnino Valladares. Manaus: Ed. Valer, 2018.

ZAMORA, Margarita. Lenguaje, autoridad e historia indigena en los Comentarios reales de los Incas. Trad. Juan Rodríguez Piñeiro; Revisão e correção Vanina M. Teglia. Lima: Centro de Estudios Literarios Antonio Cornejo Polar, CELACP / Latinoamericana Editores, 2018.

Elena Palmero González tem Graduação em Filologia Hispânica (1983) e Doutorado em Ciências Filológicas pela Universidad Central de Las Villas (Cuba, 1997). Fez estágios de pós-doutorado, na área da Literatura Latino-americana, na Université Paris IV-Sorbonne (França, 2005-2007), na Universidade de São Paulo (Brasil, 2016) e realizou um Estágio Sênior (CAPES) em Yale University (Estados Unidos, 2017). Atualmente, é Professora Titular de Literaturas Hispano-americanas da Universidade Federal do Rio de Janeiro (UFRJ) e bolsista de Produtividade em Pesquisa do CNPq. É Editora chefe da revista Alea: Estudos Neolatinos e líder do grupo de pesquisa Estudos Literários Interamericanos e Transatlânticos (UFRJ). Atua nas linhas de pesquisa da Literatura comparada e da História da literatura, com ênfase na literatura cubana, latino-americana e nas relaçóes literárias interamericanas.

E-mail: elenacpgonzalez@gmail.com 


\section{ERRATA}

No Editorial: Estudos Coloniais. Alea, v.22, n.1, p.9-11, 2020. doi 10.1590/10.1590/1517-106X/2020221911,

página 9, onde se lia:

Estudos Coloniais

Colonial Studies

\section{leia-se:}

Apresentação do v. 22, n.1, 2020, de Alea. Estudos Neolatinos

Presentation of v. 22, issue 1, of Alea. Estudos Neolatinos 